\title{
miR-129 predicts prognosis and inhibits cell growth in human prostate carcinoma
}

\author{
SONG XU*, XIAO-MING YI* Z ZHENG-YU ZHANG, JING-PING GE and WEN-QUAN ZHOU \\ Department of Urology, Jinling Hospital, School of Medicine, Nanjing University, Nanjing, Jiangsu 210002, P.R. China
}

Received October 20,2015; Accepted September 20, 2016

DOI: $10.3892 / \mathrm{mmr} .2016 .5859$

\begin{abstract}
MicroRnAs (miRNAs) are a class of small, well-conserved, non-coding RNAs that are increasingly identified as diagnostic and prognostic biomarkers in a number of cancers. Deregulated miR-129 is closely associated with tumorigenesis and cancer progression. However, the potential role of miR-129 in prostate cancer remains largely elusive. The present study investigated the role of miR-129 as a prognostic biomarker for tumor progression and clinical prognosis in prostate cancer patients. The examined prostate cancer tissues exhibited a significant reduction in miR-129 expression compared with the normal tissues $(\mathrm{P}=0.013)$. The expression levels of miR-129 were negatively correlated with histological grade $(\mathrm{P}<0.001)$, high preoperative prostate-specific antigen serum levels $(\mathrm{P}<0.001)$, pathological stage $(\mathrm{P}<0.001)$, high Gleason score $(\mathrm{P}<0.001)$, lymph node metastasis $(\mathrm{P}=0.002)$, angiolymphatic invasion $(\mathrm{P}=0.018)$, and biochemical recurrence $(\mathrm{BCR} ; \mathrm{P}=0.001)$. Use of the Kaplan-Meier analysis demonstrated that low miR-129 expression was closely associated with poorer BCR-free survival. Multivariate survival analysis indicated that miR-129 expression may be an independent prognostic marker for BCR-free survival in prostate cancer patients $(\mathrm{P}<0.001)$. Overexpression of miR-129 markedly attenuated prostate cancer cell growth by rescuing cell cycle-regulated protein expression. The present study suggests that miR-129 is downregulated in the cancerous tissues of prostate cancer patients, which was associated with poor BCR-free survival. Thus, it may be considered as a novel independent prognostic biomarker for prostate cancer. In addition, downregulation of miR-129 may serve a critical role in the proliferation of prostate cancer cells.
\end{abstract}

Correspondence to: Professor Wen-Quan Zhou, Department of Urology, Jinling Hospital, School of Medicine, Nanjing University, 305 Zhongshan East Road, Nanjing, Jiangsu 210002, P.R. China E-mail: zhouwenquannj@sina.com

*Contributed equally

Key words: microRNA-129, prostate cancer, progress, proliferation, cell cycle regulatory protein

\section{Introduction}

Cancer is recognized as a major cause for mortality worldwide. In men, prostate cancer is one of the most prevalent of these malignancies, and is considered to be the second leading cause of cancer-associated death in males in many western countries (1). The morbidity rate of prostate cancer is currently increasing at an astonishing rate in developing countries (2). Prostate cancer presents clinically as a multifocal disease with a slow progression, and demonstrates a highly aggressive level of malignant neoplasia (3). The five-year survival rate of prostate cancer patients was only $29 \%$ in 2008 , and the disease has now developed into a critical public health problem (4). A recent study has revealed that the 5-year biochemical recurrence-free survival rate is $82.1 \%$ in patients with localized prostate cancer who received radical prostatectomy treatment (5). Despite intensive study of prostate cancer, the mechanisms by which tumorigenesis and cancer progression occur have yet to be fully defined. Although there are substantial efforts to improve therapy for patients, the options for treatment of advanced prostate cancer are relatively few in number. Since 1990, the annual morbidity rate of prostate cancer has increased by $14 \%$ (6). This is largely attributed to limited knowledge concerning the initiation, growth, invasion and metastasis of prostate cancer, as well as the poor range of effective novel therapeutics that are available for those diagnosed at different stages in progression of the cancer. The conventional diagnosis for prostate cancer involves prostate-specific antigen (PSA) measurement, digital rectal examination and needle biopsy (7). Whilst the detection of PSA has greatly improved the detection rate of early prostate cancer, a needle biopsy is often recommended to further examine the histologic evidence (even in cases when an increased PSA level is detected). Accumulating evidence suggests that the PSA measurement is insufficient to predict both aggressive and indolent prostate cancer, with the U.S. Preventive Services Task Force suggesting removal of this conventional screening method from clinical practice (8). Current clinicopathological parameters, including the Gleason score, pathological grade, lymph node metastasis and tumor volume, have been considered as prognostic factors for prostate cancer (9). However, these parameters remain inadequate to distinguish between different forms of prostate cancer (10). It is therefore crucial to identify novel molecular targets in order to facilitate the early diagnosis of prostate cancer. 
MicroRNAs (miRNAs) are small 18-25 nucleotide non-coding RNA molecules with highly conserved features. They serve important roles in the initiation, development and metastasis of many cancers, and are associated with the regulation of cell growth, migration and invasion (11). It has been demonstrated that various cancers exhibit aberrant expression of miRNAs (12). Deregulated miRNAs are essential mediators for cancer pathogenesis by functioning as oncogenes or tumor suppressor genes (13). An increasing number of studies have explored the association between cancer and miRNAs, and several miRNAs have been identified as biomarkers or therapeutic targets for a number of human cancers (14). Recent studies have demonstrated that miR-129 serves an important role in tumor cell growth and invasion in hepatocellular carcinoma (15) and in lung cancer cells (16). However, the role of miR-129 in prostate cancer remains largely elusive. In the present study, the association between miR-129 expression, clinicopathological features and the prognosis of prostate cancer patients was investigated.

\section{Materials and methods}

Ethics statement. Approval of this study protocol was obtained from the Ethics Committee of Jinling Hospital (Nanjing, China), and written informed consent was provided from all subjects. All experiments were performed in accordance with the relevant guidelines and regulations of Nanjing University (Nanjing, China). This study conformed to the principles outlined in the Declaration of Helsinki adopted by the World Medical Association's General Assembly (17).

Subjects. A total of 118 prostate cancer patients admitted to Jinling Hospital (Department of Urology, Nanjing University) between 2000 and 2007, were included in this study. All patients had undergone a radical prostatectomy, and had not received chemotherapy, radiation therapy or androgen-deprivation treatment. Prostate cancer tissue samples were placed into $10 \%$ buffered formalin, and then subjected to gradient dehydration, wax dipping and embedding. Sections $(5-\mu \mathrm{m}$ thick) of each sample were placed on glass slides, dewaxed, dehydrated and stained with hematoxylin-eosin. All paraffin-embedded tissues for each sample were subject to histopathological examination by hematoxylin-eosin staining. The histopathological grading of samples for all cases was performed by experienced pathologists on hematoxylin-eosin stained sections to confirm diagnosis and tumor content as $>70 \%$ prostate cancer cells in the tissue samples. The clinicopathological and demographic data pre- and post-operation were preserved in medical records. The biochemical and clinicopathological parameters for each patient, including clinical stage, Gleason score (18), margin status, angiolymphatic invasion status, seminal vesicle invasion status and biochemical recurrence were all recorded. The summary of clinicopathological characteristics for all patients is presented in Table I. The biochemical recurrence (BCR) is a surrogate endpoint when PSA levels are $\geq 0.2 \mathrm{ng} / \mathrm{ml}$ in the patient's serum following surgical treatment. The date of prostatectomy was recognized as the beginning of the follow-up period. Any patients that did not survive due to unexpected events or diseases other than prostate cancer were excluded from the study. The primary prostate cancer tissues and paired noncancerous prostate tissues from 118 cases were collected and frozen in liquid nitrogen and stored at $-80^{\circ} \mathrm{C}$ prior to use.

$R N A$ isolation and reverse transcription-quantitative polymerase chain reaction (RT- $q P C R)$. The TRIzol reagent (Thermo Fisher Scientific, Waltham, MA, USA) was used to extract the total RNA from 118 normal and cancerous prostate tissues, according to the manufacturer's instructions. The concentration and purity of extracted RNA were measured at 260 and $280 \mathrm{~nm}$ optical densities. Reverse transcription of the RNA was then performed using the PrimeScript RT-PCR kit (Takara Bio Inc., Otsu, Japan), according to the manufacturer's instructions. The cDNA served as a template for qPCR detection using SYBR Premix Ex Taq ${ }^{\mathrm{TM}}$ (Takara Bio Inc.) and the StepOnePlus Real-Time PCR System (Applied Biosystems; Thermo Fisher Scientific, Inc.). The U6 gene served as an internal control, as described previously (19). The PCR cycling conditions were as follows: Initial denaturation at $95^{\circ} \mathrm{C}$ for $5 \mathrm{~min}$, followed by 40 cycles of denaturation at $94^{\circ} \mathrm{C}$ for $45 \mathrm{sec}$, annealing at $50^{\circ} \mathrm{C}$ for $1 \mathrm{~min}$ and extension at $72^{\circ} \mathrm{C}$ for $1 \mathrm{~min}$. Samples were analyzed in triplicate and gene expression was quantified by normalizing target gene expression to that of the internal control using the $2^{-\Delta \Delta \mathrm{Cq}} \operatorname{method}(20)$. The primer sequences used were as follows: miR-129 forward, 5'-GATACTCACTTTTTGCGGTCT-3' and reverse, 5'-GTG CAGGGTCCGAGGT-3'; U6 forward, 5'-CGCTTCGGCAGC ACATATAC-3' and reverse, 5'-CAGGGGCCATGCTAA TCTT-3' (21).

Cell culture and transfection. The prostate cell lines, PC-3 and DU145, were purchased from the Cell Bank of Chinese Academy of Sciences (Shanghai, China). The cells were cultured in RPMI 1640 medium (Gibco; Thermo Fisher Scientific, Inc.) supplemented with $10 \%$ fetal bovine serum (Gibco; Thermo Fisher Scientific, Inc.), 1\% penicillin/streptomycin (Gibco; Thermo Fisher Scientific, Inc.), $1 \%$ nonessential amino acids (Gibco; Thermo Fisher Scientific, Inc.) and $1 \%$ $(1 \mathrm{mg} / \mathrm{ml})$ sodium pyruvate (Gibco; Thermo Fisher Scientific, Inc.) at $37^{\circ} \mathrm{C}$ in a humidified incubator with $5 \% \mathrm{CO}_{2}$. The day before transfection, PC-3 and DU145 cells $\left(2 \times 10^{6}\right)$ were seeded into a six-well plate, and the transient transfection of miR-129 precursor or scramble mimic miRNA (Ambion, Carlsbad, CA, USA) was conducted using Lipofectamine 2000 Transfection Reagent (Invitrogen; Thermo Fisher Scientific, Inc.) for $48 \mathrm{~h}$, according to the manufacturer's instructions. The cells in the control group were treated with transfection reagent only.

Cell proliferation assay. Cell proliferation was assessed using the Cell Counting Kit-8 assay (CCK-8; Molecular Technologies, Inc., Kumamoto, Japan), in accordance with the manufacturer's suggestions. The absorbance, measured at a wavelength of $450 \mathrm{~nm}$, was recorded on days 1,2 and 4 post-transfection. At $96 \mathrm{~h}$ following transfection, the cells were harvested to determine the protein expression levels of proliferating cell nuclear antigen (PCNA) and phosphorylated histone $\mathrm{H} 3$ (P-H3).

Western blot analysis. The PC-3 and DU-145 prostate cell lines were transfected with either the miR-129 precursor or the 
scramble mimic negative control for $96 \mathrm{~h}$ and were harvested using a lysis buffer (Beyotime Institute of Biotechnology, Haimen, China) supplemented with EDTA-free Halt ${ }^{\mathrm{TM}}$ Protease Inhibitor Cocktail (Pierce; Thermo Scientific, Inc.). The total protein concentration of the supernatant was quantified using a bicinchoninic protein assay kit (Pierce; Thermo Scientific, Inc.). Equal amounts of protein $(40 \mu \mathrm{g})$ for each sample were loaded onto a 8 or $10 \%$ SDS gel and transferred to Immobilon-P polyvinylidene difluoride membranes (EMD Millipore, Billerica, MA, USA). The membranes were incubated with the following primary antibodies overnight at $4^{\circ} \mathrm{C}$ : Rabbit anti-PCNA (1:200; catalog no. sc-9857-R), mouse anti-P-H3 (1:200; catalog no. sc-374669) and mouse anti-GAPDH (1:200; catalog no. sc-47724), obtained from Santa Cruz Biotechnology, Inc. (Dallas, TX, USA); and rabbit anti-cyclin E (1:1,000; catalog no. 20808), rabbit anti-cyclin D1 (1:1,000; catalog no. 2978), rabbit anti-p21 (1:1,000; catalog no. 2947) and rabbit anti-p27 (1:1,000; catalog no. 3686), purchased from Cell Signaling Technology, Inc., (Danvers, MA, USA). Membranes were subsequently incubated with an anti-rabbit (1:200; catalog no. sc-2385; Santa Cruz Biotechnology, Inc.) or anti-mouse (1:200; catalog no. sc-2380; Santa Cruz Biotechnology, Inc.) horseradish peroxidase-conjugated secondary antibody for $1 \mathrm{~h}$ at room temperature. Protein bands were visualized by use of an enhanced chemiluminescence detection kit (Thermo Fisher Scientific, Inc.). Densitometric analysis of the band intensities was measured and normalized to the band intensities of GAPDH using the ImageJ software version 1.48 (National Institutes of Health, Bethesda, MA, USA).

Statistical analysis. Continuous variables are expressed as the mean \pm standard deviation. SPSS 19.0 software (SPSS Inc., Chicago, IL, USA) was used for statistical analysis. The Kolmogorov-Smirnov test was used to determine the normality of the data distribution. Comparisons between two groups were assessed using the Student's $t$-test. One-way or two-way analysis of variance followed by a post-hoc Bonferroni test was used for multiple comparisons. The test for categorical variables was determined using the $\chi^{2}$ test, and the small cell variables were compared using Fisher's exact test. Survival analysis was conducted with the Kaplan-Meier method. Multivariate analyses were performed using the Cox proportional hazards model. $\mathrm{P}<0.05$ was considered to indicate a statistically significant difference.

\section{Results}

Downregulation of miR-129 expression in prostate cancer tissues. The miR-129 expression levels in 118 paired prostate cancer and adjacent non-cancerous prostate tissues were measured by RT-qPCR analysis. The results demonstrated that the expression of miR-129 at the mRNA level was significantly reduced in the prostate cancer tissues when compared with non-cancerous prostate tissues ( $\mathrm{P}=0.013$; Fig. 1$)$. In addition, the median relative quantity of miR-129 expression in the 118 prostate cancer tissues was equal to 1.01 (Fig. 1). Therefore, the number of prostate cancer patients with low miR-129 expression was 52, and the number with high miR-129 expression was 66 .

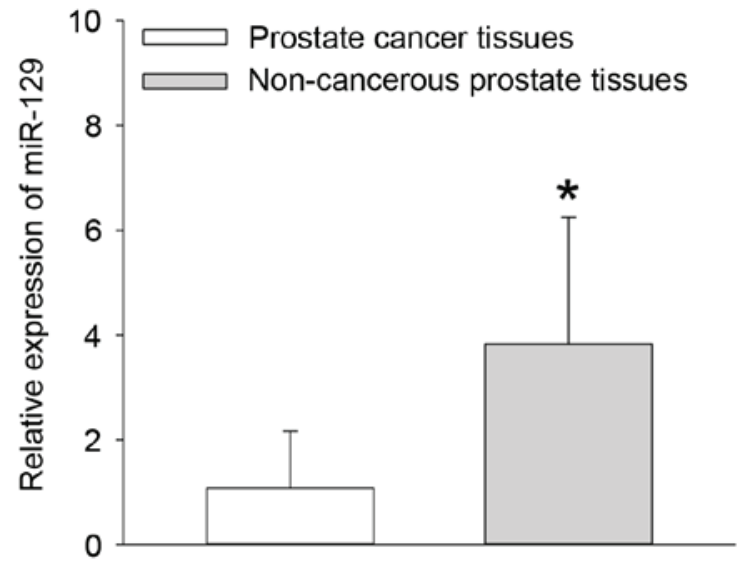

Figure 1. Expression levels of miR-129 were detected and analyzed in 118 paired prostate cancer and adjacent non-cancerous prostate tissue samples by RT-qPCR analysis. The results demonstrated that miR-129 expression levels were significantly decreased in prostate cancer tissues compared to those in adjacent non-cancerous prostate tissues. ${ }^{*} \mathrm{P}<0.05$ vs. prostate cancer tissues. miR-129, microRNA-129; RT-qPCR, reverse transcription-quantitative polymerase chain reaction.

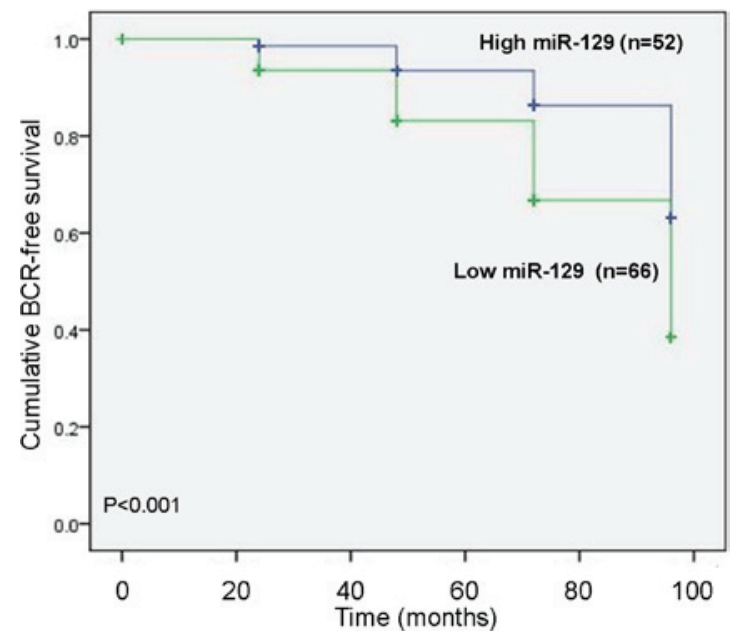

Figure 2. Kaplan-Meier BCR-free survival curves for two groups defined by low and high expression of miR-129 in subjects with prostate cancer. The patients with higher miR-129 expression exhibited significantly higher BCR-free survival rates following radical prostatectomy compared with patients with low miR-129 expression $(\mathrm{P}<0.001)$. BCR, biochemical recurrence; miR-129, micro RNA-129.

Correlation of miR-129 expression with the clinical parameters of prostate cancer patients. As demonstrated in Table I, low expression of miR-129 in the prostate cancer tissues was closely correlated with aggressive clinical pathological parameters including histological grade $(\mathrm{P}<0.001)$, high preoperative PSA level $(\mathrm{P}<0.001)$, pathological stage $(\mathrm{P}<0.001)$, a high Gleason score $(\mathrm{P}<0.001)$, lymph node metastases $(\mathrm{P}=0.002)$, angiolymphatic invasion $(\mathrm{P}=0.018)$ and $\mathrm{BCR}(\mathrm{P}=0.001)$. No association between the expression level of miR-129 and additional clinical factors such as age and surgical margin status was observed (all $\mathrm{P}>0.05$ ).

Association between miR-129 expression and BCR-free survival. To assess the possible prognostic value of using miR-129 as a biomarker in prostate cancer tissues, the 
Table I. Correlation of miR-129 expression with the clinicopathological characteristics of 118 prostate cancer patients.

\begin{tabular}{|c|c|c|c|c|c|}
\hline \multirow[b]{2}{*}{ Variable } & \multirow[b]{2}{*}{ Cases $(\%)$} & \multicolumn{2}{|c|}{ miR-129 expression (\%) } & \multirow[b]{2}{*}{$\chi^{2}$} & \multirow[b]{2}{*}{ P-value } \\
\hline & & Low & High & & \\
\hline \multicolumn{6}{|l|}{ Age } \\
\hline$\leq 60$ & $71(60.2)$ & $41(57.8)$ & $30(42.2)$ & \multirow[t]{2}{*}{0.238} & \multirow[t]{2}{*}{0.626} \\
\hline$>60$ & $47(39.8)$ & $25(53.2)$ & $22(46.8)$ & & \\
\hline \multicolumn{6}{|c|}{ Histological grade } \\
\hline $\mathrm{G} 1+\mathrm{G} 2$ & $65(55.1)$ & $25(38.5)$ & $40(61.5)$ & \multirow[t]{2}{*}{17.921} & \multirow[t]{2}{*}{$<0.001$} \\
\hline G3 & $53(44.9)$ & $41(77.4)$ & $12(22.6)$ & & \\
\hline \multicolumn{6}{|c|}{ Preoperative PSA } \\
\hline$<4 \mathrm{ng} / \mathrm{ml}$ & $4(3.4)$ & $0(0)$ & $4(100)$ & \multirow[t]{3}{*}{33.332} & \multirow[t]{3}{*}{$<0.001$} \\
\hline $4-10 \mathrm{ng} / \mathrm{ml}$ & $30(25.4)$ & $5(16.7)$ & $25(83.3)$ & & \\
\hline$>10 \mathrm{ng} / \mathrm{ml}$ & $84(71.2)$ & $61(72.6)$ & $23(27.4)$ & & \\
\hline \multicolumn{6}{|c|}{ Pathological stage } \\
\hline $\mathrm{I}+\mathrm{II}$ & $77(65.3)$ & $32(41.6)$ & $45(58.4)$ & \multirow[t]{2}{*}{18.576} & \multirow[t]{2}{*}{$<0.001$} \\
\hline III + IV & $41(34.7)$ & $34(82.9)$ & $7(17.1)$ & & \\
\hline \multicolumn{6}{|c|}{ Gleason score } \\
\hline$<7$ & $36(30.5)$ & $11(30.6)$ & $25(69.4)$ & \multirow[t]{3}{*}{25.345} & \multirow[t]{3}{*}{$<0.001$} \\
\hline 7 & $50(42.4)$ & $26(52.0)$ & $24(48.0)$ & & \\
\hline$>7$ & $32(27.1)$ & $29(90.6)$ & $3(9.4)$ & & \\
\hline \multicolumn{6}{|c|}{ Lymph node metastasis } \\
\hline Negative & $103(87.3)$ & $52(50.5)$ & $51(49.5)$ & \multirow[t]{2}{*}{9.753} & \multirow[t]{2}{*}{0.002} \\
\hline Positive & $15(12.7)$ & $14(93.3)$ & $1(6.7)$ & & \\
\hline \multicolumn{6}{|c|}{ Surgical margin status } \\
\hline Negative & $99(83.9)$ & $56(56.6)$ & $43(43.4)$ & \multirow[t]{2}{*}{0.100} & \multirow[t]{2}{*}{0.752} \\
\hline Positive & $19(16.1)$ & $10(52.6)$ & $9(47.4)$ & & \\
\hline \multicolumn{6}{|c|}{ Angiolymphatic invasion } \\
\hline Negative & $82(69.5)$ & $40(48.8)$ & $42(51.2)$ & \multirow[t]{2}{*}{5.577} & \multirow[t]{2}{*}{0.018} \\
\hline Positive & $36(30.5)$ & $26(72.2)$ & $10(27.8)$ & & \\
\hline \multicolumn{6}{|c|}{ Biochemical recurrence } \\
\hline Negative & $89(75.4)$ & $42(47.2)$ & $47(52.8)$ & \multirow[t]{2}{*}{11.226} & 0.001 \\
\hline Positive & $29(24.6)$ & $24(82.8)$ & $5(17.2)$ & & \\
\hline
\end{tabular}

miR-129, micro-RNA-129; PSA, prostate-specific antigen.

BCR-free survival in 118 prostate cancer patients undergoing radical prostatectomy was performed by calculating the cumulative survival curves using the Kaplan-Meier method. The Kaplan-Meier curves plotted with high or low miR-129 expression levels and BCR-free survival, indicated that prostate cancer patients with low miR-129 expression levels exhibited a significantly shorter BCR-free survival compared with those with high miR-129 expression levels ( $\mathrm{P}<0.001$; Fig. 2). As summarized in Table II, the univariate survival analysis with Cox proportional hazards model revealed that the impact of well-known clinicopathological prognostic features, including miR-129 expression $(\mathrm{P}<0.001)$, Gleason score $(\mathrm{P}<0.001)$, histological grade $(\mathrm{P}=0.002)$, pathological stage $(\mathrm{P}<0.001)$, lymph node metastasis $(\mathrm{P}=0.006)$ and angiolymphatic invasion $(\mathrm{P}=0.005)$ were significantly associated with $\mathrm{BCR}$-free survival in prostate cancer patients. Since variables that are determined to have a prognostic influence by univariate analysis may covariate, a multivariate analysis of the association between miR-129 expression levels and the BCR-free survival of patients with prostate cancer was performed. The Cox multivariate analysis confirmed the significance of BCR-free survival with miR-129 expression $(\mathrm{P}<0.001)$, as well as histological grade $(\mathrm{P}=0.002)$, pathological stage $(\mathrm{P}<0.001)$, lymph node metastasis $(\mathrm{P}<0.001)$ and angiolymphatic invasion $(\mathrm{P}<0.001)$ as independent prognostic predictors of $\mathrm{BCR}$-free survival of prostate cancer patients (Table III).

Effects of miR-129 on prostate cancer cell growth. The miR-129 precursor or scramble mimic negative control was transfected to PC-3 and DU-145 prostate cell lines in order to determine the effect of miR-129 on prostate cancer cell proliferation in vitro. As shown in Table IV, overexpression of miR-129 effectively attenuated the proliferation rate of PC-3 and DU-145 prostate cell lines at days 2 and 4 post-transfection, 
Table II. Univariate survival analysis of BCR-free survival in 118 prostate cancer patients.

\begin{tabular}{|c|c|c|c|}
\hline \multirow[b]{2}{*}{ Variables } & \multicolumn{3}{|c|}{ BCR-free survival } \\
\hline & $\operatorname{Exp}(\mathrm{B})$ & $95 \% \mathrm{CI}$ & P-value \\
\hline Age $(\leq 60$ vs. $>60)$ & 1.067 & $0.802-1.421$ & 0.653 \\
\hline Histological grade (G1+G2 vs. G3) & 2.115 & $0.275-1.224$ & 0.002 \\
\hline Preoperative PSA (<10 ng/ml vs. $\geq 10 \mathrm{ng} / \mathrm{ml})$ & 1.091 & $0.918-1.294$ & 0.317 \\
\hline Pathological stage (T1-2 vs. T3-4) & 4.524 & $0.883-2.136$ & $<0.001$ \\
\hline Gleason score (4-6 vs. 7-10) & 3.745 & $0.698-1.725$ & $<0.001$ \\
\hline Lymph node metastasis (negative vs. positive) & 1.941 & $0.189-1.138$ & 0.006 \\
\hline Surgical margin status (negative vs. positive) & 1.015 & $0.714-2.192$ & 0.927 \\
\hline Angiolymphatic invasion (negative vs. positive) & 1.508 & $1.134-2.005$ & 0.005 \\
\hline miR-129 expression (high vs. low) & 5.627 & $1.124-11.392$ & $<0.001$ \\
\hline
\end{tabular}

BCR, biochemical recurrence; PSA, prostate-specific antigen; miR-129, microRNA-129.

Table III. Multivariate survival analysis of BCR-free survival in 118 prostate cancer patients.

BCR-free survival

\begin{tabular}{lcrr} 
Variables & Exp (B) & 95\% CI & P-value \\
\hline Histological grade (G1+G2 vs. G3) & 2.123 & $0.279-1.228$ & 0.002 \\
Pathological stage (T1-2 vs. T3-4) & 3.818 & $0.776-1.913$ & $<0.001$ \\
Lymph node metastasis (negative vs. positive) & 4.505 & $0.932-2.078$ & $<0.001$ \\
Angiolymphatic invasion (negative vs. positive) & 3.511 & $0.717-1.795$ & $<0.001$ \\
miR-129 expression (high vs. low) & 2.692 & $0.441-1.539$ & $<0.001$
\end{tabular}

BCR, biochemical recurrence; miR-129, microRNA-129.

Table IV. CCK-8 assay for the growth of PC-3 and DU-145 prostate cancer cell lines transfected with miR-129 precursor or negative control miRNA and measured at days 1,2, and 4 post-transfection.

\begin{tabular}{lccccc}
\hline Cell line & Indicated transfection & $\mathrm{OD}_{450}$ at day 0 & $\mathrm{OD}_{450}$ at day 1 & $\mathrm{OD}_{450}$ at day 2 & $\mathrm{OD}_{450}$ at day 4 \\
\hline PC-3 & Negative miRNA & $0.214 \pm 0.016$ & $0.532 \pm 0.045$ & $0.834 \pm 0.079$ & $1.231 \pm 0.098$ \\
& miR-129 & $0.225 \pm 0.019$ & $0.510 \pm 0.056$ & $0.621 \pm 0.066^{\mathrm{a}}$ & $0.813 \pm 0.085^{\mathrm{a}}$ \\
DU-145 & Negative miRNA & $0.216 \pm 0.021$ & $0.652 \pm 0.078$ & $0.948 \pm 0.095$ & $1.422 \pm 0.113$ \\
& miR-129 & $0.209 \pm 0.025$ & $0.643 \pm 0.069$ & $0.724 \pm 0.043^{\mathrm{a}}$ & $0.933 \pm 0.105^{\mathrm{a}}$ \\
\hline
\end{tabular}

Data are presented as the mean \pm standard deviation $(\mathrm{n}=6)$. CCK- 8 , cell counting kit-8; miR-129, microRNA-129; OD, optical density. ${ }^{\mathrm{a}} \mathrm{P}<0.05$ vs. negative miRNA.

as determined using the CCK8 assay. In addition, the protein expression levels of cell proliferation markers PCNA and $\mathrm{P}-\mathrm{H} 3$ were significantly reduced in PC-3 and DU-145 cells at 4 days following transfection with miR-129 precursor, compared with untreated and negative controls (Fig. 3).

Inhibitory effects of miR-129 on the protein expression levels of cell cycle regulators. Cell cycle progression is associated with cell proliferation, therefore the present study aimed to clarify whether inhibition of cell growth by miR-129 involves the regulation of cell cycle-associated proteins cyclin E, cyclin D1, p27 and p21. Compared with untreated and negative controls, the protein expression levels of cyclin E and cyclin D1 were significantly reduced in PC-3 and DU-145 cells following transfection with miR-129 ( $\mathrm{P}=0.013$; Fig. 4). By contrast the protein expression levels of p27 and p21 in both cell lines were significantly increased when compared with untreated and negative controls ( $\mathrm{P}=0.021$; Fig. 4). These results suggest that miR-129 may exert an inhibitory effect on the proliferation of prostate cancer cells by inducing of cell cycle arrest. 

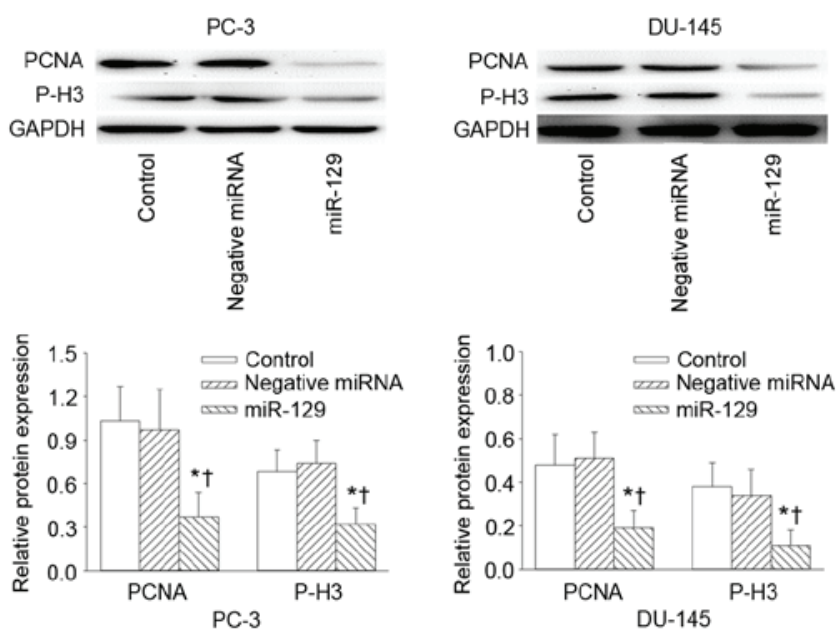

Figure 3. Effect of miR-129 on PCNA and P-H3 protein expression in prostate cancer cell lines. At 4 days after transfection of PC-3 and DU-145 cells with miR-129 precursor or negative miRNA, the PCNA and P-H3 expression levels were determined using western blot analysis. GAPDH was used as a loading control. Data are presented as the mean \pm standard deviation $(n=3)$. ${ }^{*} \mathrm{P}<0.05$ vs. control; ${ }^{\dagger} \mathrm{P}<0.05$ vs. negative miRNA. miR-129, microRNA-129, PCNA, proliferating cell nuclear antigen; P-H3, phosphorylated histone 3.
PC-3
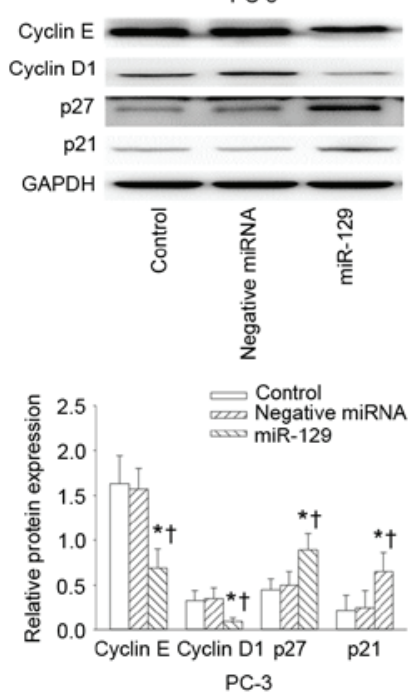

DU-145
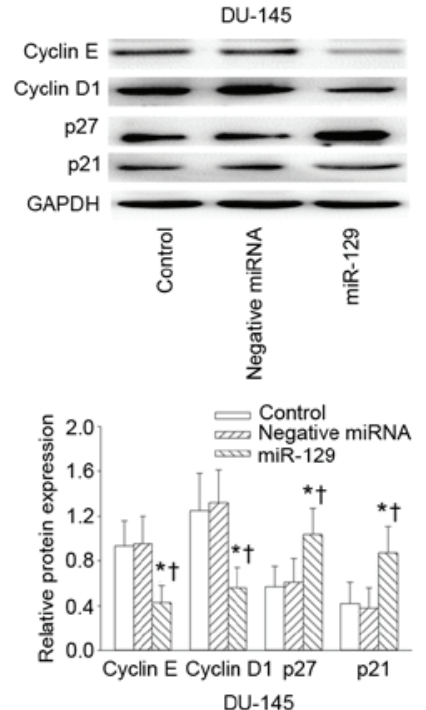

Figure 4. Effect of miR-129 on the expression of cell cycle-associated proteins in prostate cancer cell lines. At 4 days after transfection of miR-129 precursor or negative miRNA in PC-3 and DU-145 prostate cell lines, the protein expression levels of cyclin E, cyclin D1, p27, p21 and GAPDH in PC-3 (left panel) and DU-145 (right panel) were determined by western blot analysis. Data are presented as the mean \pm standard deviation $(n=3)$. $P<0.05$ vs. control; ' $\mathrm{P}<0.05$ vs. negative miRNA. miR-129, microRNA-129.

\section{Discussion}

The present study established an association between miR-129 and aggressive clinicopathological parameters in prostate cancer patients. miR-129 may be a crucial component in the pathogenesis and aggressiveness of prostate cancer, and downregulation of its expression may be closely correlated with unfavorable prognosis in prostate cancer patients.

Prostate cancer is a prevalent malignancy in developed and developing countries and is a significant global clinical burden, accounting for $>92,300$ mortalities each year (22). The lack of sufficient diagnostic and prognostic factors are primary causes for poor clinical outcome in prostate cancer patients. It has been proposed that an early and accurate diagnosis of prostate cancer would be essential for determining an appropriate treatment strategy (23). Despite the fact that patients with localized prostate cancer that have undergone a radical prostatectomy have favorable long-term survival rates, long-term follow-ups have demonstrated that BCR occurs in $\sim 50 \%$ of patients following surgery (24). Hence, it is necessary to evaluate the early risk of BCR in order to improve the prognosis for patients. Conventional prognostic factors, including the Gleason score or measuring preoperative PSA levels, are limited for the diagnosis of early prostate cancer (25). A previous study demonstrated that Golgi phosphoprotein-3 expression was associated with androgen-independence, bone metastases, a higher Gleason scale score and higher baseline PSA levels, and serves as a significant independent prognostic factor for disease-free survival in prostate cancer patients (26). In addition, RNA-binding protein (RBM3) expression was observed to be increased in the prostate intraepithelium, which was associated with a prolonged time to disease progression (27). It was therefore suggested that RBM3 may be employed as a useful independent biomarker of favorable prognosis for prostate cancer (27). In addition, a recent study discovered that high transformer $2 \beta$ (Tra2 $\beta$ ) expression levels are significantly associated with a high Gleason score, clinical stage, lymph node metastases, and BCR in subjects with prostate cancer, and overexpression of Tra $2 \beta$ may be a possible predictor for poor BCR-free survival (28). These studies demonstrate the unremitting efforts that have been made by many researchers so far in order to attempt to uncover efficient diagnostic and prognostic biomarkers for prostate cancer.

miRNAs serve an important role in numerous biological processes in tumors, including cell proliferation, apoptosis and migration and invasion. Over 1,400 human miRNA sequences are known to be involved in cancer pathogenesis (29). In recent years, miRNAs have been demonstrated to function as molecular prognostic biomarkers for a number of cancers. For example, it has been reported that miR-188-5p expression levels are significantly downregulated in metastatic prostate cancer tissues, and miR-188-5p is predicted to be an independent prognostic marker for BCR-free survival, as well as overall survival in prostate cancer patients (30). In addition, miR-221 is also significantly downregulated in prostate cancer patients with lymph node-metastases, and is employed as a biomarker for the clinical prognosis of high-risk prostate cancer patients (31). By contrast, miR-96 is overexpressed in prostate cancer tissues and is closely associated with a poor median survival of 3 years (32). The results of these studies suggest that miRNAs are emerging as potential prognostic biomarkers or useful therapeutic targets in prostate cancer. miR-129 is a diagnostic and prognostic biomarker in gastrointestinal cancer, which exhibits suppressive activities that may lead to inhibition of tumorigenesis, tumor cell proliferation and invasion, and disease progression (33). In addition, miR-129 was recently observed to be downregulated in gastric cancer $(34,35)$, colorectal cancer $(34,35)$, liver cancer $(36)$ and lymphocytic leukemia (37). RT-qPCR results demonstrated that miR-129-3p gene expression was extensively attenuated 
in human renal cell carcinoma, and this low expression was a predictor of reduced disease-free and overall survival in renal cell carcinoma patients (37). miR-129 expression in bladder cancer patients has been demonstrated to be lower when compared with normal noncancerous controls, thus miR-129 is suggested to be a predictive marker of the progression of bladder tumors (38). However, the role of miR-129 in prostate cancer patients remains largely elusive. The results of the present study demonstrate a significant reduction in miR-129 gene expression levels in prostate cancer tissues when compared with adjacent non-cancerous prostate tissues. Further analysis indicated that downregulation of miR-129 gene expression was positively associated with histological grade, high preoperative PSA levels, pathological stage, a high Gleason score, lymph node metastases, angiolymphatic invasion and BCR in prostate cancer patients. In addition, prostate cancer patients with low miR-129 expression exhibited poor BCR-free survival. The multivariate analyses clarified that reduced miR-129 expression may be an independent prognostic indicator of BCR-free survival in prostate cancer patients. These results suggest that miR-129 may provide a novel and important prognostic biomarker for prostate cancer.

Excessive cell proliferation in prostate cancer tissues is positively associated with tumorigenesis and tumor progression (39). In bladder carcinoma cell lines, transfection with a miR-129 precursor significantly inhibited the growth and induced cell death in T24 and SW780 cells (38). In hepatocellular carcinomas, transfection with miR-129 mimics remarkably attenuated the proliferation and invasion of hepatocellular carcinoma cells (15). Ectopic expression of miR-129-5p significantly inhibited the growth and migration of medullary thyroid carcinoma cells by targeting the proto-oncogene pathway (40). The results of the present study demonstrated that miR-129 gene overexpression attenuated the proliferation of PC-3 and DU-145 prostate cancer cell lines. This was evidenced by the CCK- 8 assay and the observed downregulation of PCNA and P-H3 in response to transfection with an miR-129 mimic. These results suggest that miR-129 may function as tumor suppressor gene in prostate cancer, and may be a potential therapeutic target in prostate cancer.

Abnormal regulation of the cell cycle is an important factor that is closely associated with the cancer development (41). Emerging evidence indicates that deregulated miRNAs are major mediators in the regulation of tumor-associated cell cycle defects (42). Multiple protein kinases that contain a regulatory cyclin component and a catalytic cyclin-dependent kinase (CDK) are necessary for cell cycle regulation during several major checkpoints of the cell cycle. The specific CDK inhibitors, p21 and p27, are negative regulators of cyclins, which inhibit the cell cycle at the G0/G1 phase (43). Overexpression of cyclin D1 is a critical step in the development of some human cancers, including prostate cancer, by encoding the regulatory subunit of a holoenzyme and promoting the progression of the G1/S phase of the cell cycle (44). Increased cyclin D1 expression is correlated with human tumorigenesis and cellular metastases, including parathyroid adenoma, breast cancer, colon cancer, lymphoma, melanoma, and prostate cancer (44). In addition, cyclin $\mathrm{E}$ has been demonstrated to promote the proliferation of prostate cancer cells (45). Introduction of an adenovirus vector harboring p27 noticeably reduced the size of human prostate cancer xenograft tumors (45) and p21 is an established tumor suppressor gene involved in human prostate cancer development (46). The present study demonstrated that miR-129 overexpression in PC-3 and DU-145 prostate cancer cell lines was associated with a reduction in the expression of cell cycle-associated proteins cyclin E and cyclin D1, and an increase in the expression of CDK inhibitors p21 and p27. These results indicate that miR-129 exerts an inhibitory effect on the growth of prostate cancer cells, potentially via a direct repressive effect on cell cycle progression. This suggests a mechanism whereby downregulation of miR-129 may contribute to the growth of malignant prostate cancer. However, future studies regarding the role of miR-129 in the migration and invasion of tumors in nude mice, as well as their underlying molecular mechanisms, are required.

In conclusion, the results of the present study demonstrated that low miR-129 expression may serve a integral role in the progression of prostate cancer, and was significantly associated with poor prognosis independently of other factors in prostate cancer. These results raise the possibility that miR-129 may be a useful prognostic parameter for prostate cancer, and may be considered as a novel molecular target for the diagnosis and treatment of prostate cancer.

\section{References}

1. Siegel R, Naishadham D and Jemal A: Cancer statistics, 2013. CA Cancer J Clin 63: 11-30, 2013.

2. Torre LA, Bray F, Siegel RL, Ferlay J, Lortet-Tieulent J and Jemal A: Global cancer statistics, 2012. CA Cancer J Clin 65: 87-108, 2015.

3. Ferlay J, Parkin DM and Steliarova-Foucher E: Estimates of cancer incidence and mortality in Europe in 2008. Eur J Cancer 46: 765-781, 2010.

4. Carroll PR: Early stage prostate cancer-do we have a problem with over-detection, overtreatment or both? J Urol 173: 1061-1062, 2005.

5. Boehm K, Schiffmann J, Tian Z, Lesmana H, Larcher A, Mandel P, Karakiewicz PI, Graefen M, Schwarz R, Krüll A and Tilki D: Five-year biochemical recurrence-free and overall survival following high-dose-rate brachytherapy with additional external beam or radical prostatectomy in patients with clinically localized prostate cancer. Urol Oncol 34: 119.e11-e18, 2016.

6. Ishizaki F, Hara N, Koike H, Kawaguchi M, Tadokoro A, Takizawa I, Nishiyama T, Takahashi K and Hohenfellner R: Prediction of pathological and oncological outcomes based on extended prostate biopsy results in patients with prostate cancer receiving radical prostatectomy: A single institution study. Diagn Pathol 7: 68, 2012.

7. Velonas VM, Woo HH, dos Remedios CG and Assinder SJ: Current status of biomarkers for prostate cancer. Int J Mol Sci 14: 11034-11060, 2013.

8. Moyer VA; U.S. Preventive Services Task Force: Screening for prostate cancer: U.S. Preventive Services Task Force recommendation statement. Ann Intern Med 157: 120-134, 2012.

9. Dabir PD, Ottosen P, Hoyer S and Hamilton-Dutoit S: Comparative analysis of three- and two-antibody cocktails to AMACR and basal cell markers for the immunohistochemical diagnosis of prostate carcinoma. Diagn Pathol 7: 81, 2012.

10. Humphrey PA and Vollmer RT: Percentage carcinoma as a measure of prostatic tumor size in radical prostatectomy tissues. Mod Pathol 10: 326-333, 1997.

11. Friedman RC, Farh KK, Burge CB and Bartel DP: Most mammalian mRNAs are conserved targets of microRNAs. Genome Res 19: 92-105, 2009.

12. Li J, Ju J, Ni B and Wang H: The emerging role of miR-506 in cancer. Oncotarget: Aug 15, 2016 (Epub ahead of print).

13. Pallante P, Visone R, Ferracin M, Ferraro A, Berlingieri MT, Troncone G, Chiappetta G, Liu CG, Santoro M, Negrini M, et al: MicroRNA deregulation in human thyroid papillary carcinomas. Endocr Relat Cancer 13: 497-508, 2006. 
14. Ohtsuka M, Ling H, Doki Y, Mori M and Calin GA: MicroRNA processing and human cancer. J Clin Med 4: 1651-1667, 2015.

15. Zhai J, Qu S, Li X, Zhong J, Chen X, Qu Z and Wu D: miR-129 suppresses tumor cell growth and invasion by targeting PAK5 in hepatocellular carcinoma. Biochem Biophys Res Commun 464: 161-167, 2015.

16. Xiao Y, Li X, Wang H, Wen R, He J and Tang J: Epigenetic regulation of miR-129-2 and its effects on the proliferation and invasion in lung cancer cells. J Cell Mol Med 19: 2172-2180, 2015

17. Malik AY and Foster C: The revised declaration of Helsinki: Cosmetic or real change? J R Soc Med 109: 184-189, 2016.

18. Miah S, Ahmed HU, Freeman A and Emberton M: Does true Gleason pattern 3 merit its cancer descriptor? Nat Rev Urol 13: 541-548, 2016

19. Xu S, Yi XM, Zhou WQ, Cheng W, Ge JP and Zhang ZY: Downregulation of miR-129 in peripheral blood mononuclear cells is a diagnostic and prognostic biomarker in prostate cancer. Int J Clin Exp Pathol 8: 14335-14344, 2015.

20. Livak KJ and Schmittgen TD: Analysis of relative gene expression data using real-time quantitative PCR and the 2(-Delta Delta C(T)) Method. Methods 25: 402-408, 2001.

21. Wang QY, Tang J, Zhou CX and Zhao Q: The down-regulation of miR-129 in breast cancer and its effect on breast cancer migration and motility. Sheng Li Xue Bao 64: 403-411, 2012 (In Chinese).

22. Wilson HC, Shah SI, Abel PD, Price P, Honeyfield L, Edwards S and Abel RL: Contemporary hormone therapy with LHRH agonists for prostate cancer: Avoiding osteoporosis and fracture. Cent European J Urol 68: 165-168, 2015.

23. Mapelli P and Picchio M: Initial prostate cancer diagnosis and disease staging-the role of choline-PET-CT. Nat Rev Urol 12 510-518, 2015

24. Molitierno J, Evans A, Mohler JL, Wallen E, Moore D and Pruthi RS: Characterization of biochemical recurrence after radical prostatectomy. Urol Int 77: 130-134, 2006.

25. Montironi R, Mazzuccheli R, Scarpelli M, Lopez-Beltran A, Fellegara $G$ and Algaba F: Gleason grading of prostate cancer in needle biopsies or radical prostatectomy specimens: Contemporary approach, current clinical significance and sources of pathology discrepancies. BJU Int 95: 1146-1152, 2005

26. Hua X, Yu L, Pan W, Huang X, Liao Z, Xian Q, Fang L and Shen H: Increased expression of Golgi phosphoprotein-3 is associated with tumor aggressiveness and poor prognosis of prostate cancer. Diagn Pathol 7: 127, 2012.

27. Jonsson L, Gaber A, Ulmert D, Uhlén M, Bjartell A and Jirström K: High RBM3 expression in prostate cancer independently predicts a reduced risk of biochemical recurrence and disease progression. Diagn Pathol 6: 91, 2011.

28. Diao Y, Wu D, Dai Z, Kang H, Wang Z and Wang X: Prognostic value of transformer $2 \beta$ expression in prostate cancer. Int J Clin Exp Pathol 8: 6967-6973, 2015.

29. Sempere LF: Integrating contextual miRNA and protein signatures for diagnostic and treatment decisions in cancer Expert Rev Mol Diagn 11: 813-827, 2011.

30. Zhang H, Qi S, Zhang T, Wang A, Liu R, Guo J, Wang Y and Xu Y: miR-188-5p inhibits tumour growth and metastasis in prostate cancer by repressing LAPTM4B expression. Oncotarget 6: 6092-6104, 2015.

31. Spahn M, Kneitz S, Scholz CJ, Stenger N, Rüdiger T, Ströbel P, Riedmiller $\mathrm{H}$ and Kneitz B: Expression of microRNA-221 is progressively reduced in aggressive prostate cancer and metastasis and predicts clinical recurrence. Int J Cancer 127: 394-403, 2010.
32. Haflidadóttir BS, Larne O, Martin M, Persson M, Edsjö A, Bjartell A and Ceder Y: Upregulation of miR-96 enhances cellular proliferation of prostate cancer cells through FOXO1. PloS One 8: e72400, 2013.

33. Fesler A, Zhai H and Ju J: miR-129 as a novel therapeutic target and biomarker in gastrointestinal cancer. Onco Targets Ther 7: $1481-1485,2014$

34. Tsai KW, Wu CW, Hu LY, Li SC, Liao YL, Lai CH, Kao HW, Fang WL, Huang KH, Chan WC and Lin WC: Epigenetic regulation of miR-34b and miR-129 expression in gastric cancer. Int $\mathrm{J}$ Cancer 129: 2600-2610, 2011.

35. Bandres E, Agirre X, Bitarte N, Ramirez N, Zarate R, Roman-Gomez J, Prosper F and Garcia-Foncillas J: Epigenetic regulation of microRNA expression in colorectal cancer. Int J Cancer 125: 2737-2743, 2009.

36. Chen X, Zhang L, Zhang T, Hao M, Zhang X, Zhang J, Xie Q, Wang Y, Guo M, Zhuang H and Lu F: Methylation-mediated repression of microRNA 129-2 enhances oncogenic SOX4 expression in HCC. Liver Int 33: 476-486, 2013.

37. Chen X, Ruan A, Wang X, Han W, Wang R, Lou N, Ruan H, Qiu B, Yang H and Zhang X: miR-129-3p, as a diagnostic and prognostic biomarker for renal cell carcinoma, attenuates cell migration and invasion via downregulating multiple metastasis-related genes. J Cancer Res Clin Oncol 140: 1295-1304, 2014.

38. Dyrskjot L, Ostenfeld MS, Bramsen JB, Silahtaroglu AN, Lamy P, Ramanathan R, Fristrup N, Jensen JL, Andersen CL, Zieger K, et al: Genomic profiling of microRNAs in bladder cancer: miR-129 is associated with poor outcome and promotes cell death in vitro. Cancer Res 69: 4851-4860, 2009.

39. Goździk-Spychalska J, Szyszka-Barth K, Spychalski L, Ramlau K, Wójtowicz J, Batura-Gabryel H and Ramlau R: C-MET inhibitors in the treatment of lung cancer. Curr Treat Options Oncol 15: 670-682, 2014.

40. Duan L, Hao X, Liu Z, Zhang Y and Zhang G: MiR-129-5p is down-regulated and involved in the growth, apoptosis and migration of medullary thyroid carcinoma cells through targeting RET. FEBS Lett 588: 1644-1651, 2014.

41. Yang Y, Pan X, Lei W, Wang J, Shi J, Li F and Song J: Regulation of transforming growth factor-beta 1-induced apoptosis and epithelial-to-mesenchymal transition by protein kinase A and signal transducers and activators of transcription 3. Cancer Res 66: 8617-8624, 2006.

42. Bao B, Ahmad A, Kong D, Ali S, Azmi AS, Li Y, Banerjee S, Padhye $S$ and Sarkar FH: Hypoxia induced aggressiveness of prostate cancer cells is linked with deregulated expression of VEGF, IL-6 and miRNAs that are attenuated by CDF. PloS One 7: e43726, 2012

43. Abukhdeir AM and Park BH: P21 and p27: Roles in carcinogenesis and drug resistance. Expert Rev Mol Med 10: e19, 2008.

44. Fu M, Wang C, Li Z, Sakamaki T and Pestell RG: Minireview: Cyclin D1: Normal and abnormal functions. Endocrinology 145: 5439-5447, 2004

45. Hashimoto Y, Naruyama H, Ando R, Okada S, Tozawa K and Kohri K: Molecular targeted therapy for prostate cancer. Hinyokika Kiyo 54: 57-61, 2008.

46. Lee JT, Lehmann BD, Terrian DM, Chappell WH, Stivala F, Libra M, Martelli AM, Steelman LS and McCubrey JA: Targeting prostate cancer based on signal transduction and cell cycle pathways. Cell Cycle 7: 1745-1762, 2008. 